
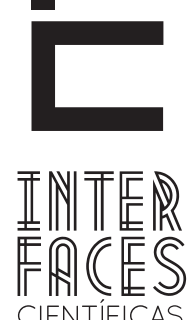

HUMANASE SOCIAIS

ISSN IMPRESSO 2316-3348

E-ISSN 2316-3801

\title{
ESCRAVIDÃO, COR, GÊNERO E MOBILLDADE SOCIAL: A TRAJETÓRIA DE ANTONIA GOMES NA CIDADE DA BAHIA SETECENTISTA
}

SLAVERY, COLOR, GENDER AND SOCIAL MOBILITY: THE TRAJECTORY OF ANTONIA GOMES IN THE CITY OF BAHIA.

ESCLAVITUD, COLOR, GÉNERO Y MOVILIDAD SOCIAL: LA TRAYECTORIA DE ANTONIA GOMES EN LA CIUDAD DE LA BAHIA SETECENTISTA.

\section{RESUMO}

0 presente artigo pretende evidenciar como o estabelecimento de relações conjugais informais também representava possibilidade de melhoria de condições de vida para a população africana na Cidade da Bahia setecentista. Para tanto, utilizamos a trajetória da africana, mina, Antonia Gomes como janela privilegiada para compreender esses aspectos e outros relativos à cor, gênero e mobilidade social no contexto da escravidão urbana no século XVIII. Com efeito, foram utilizadas como fontes inventários, testamentos, assentos de batismo e casamento.

\section{PALAVRAS-CHAVE}

Africanos. Mobilidade Social. Salvador. Século XVIII. 


\section{ABSTRACT}

This article intends to show how the establishment of informal marital relations also represented the possibility of improving living conditions for the African population in the City of Bahia in the eighteenth century. For that, I used the trajectory of the African, Mina, Antonia Gomes as a privileged window to understand these aspects and others related to color, gender and social mobility in the context of urban slavery in the eighteenth century. In effect, inventories, wills, baptism and marriage seats were used as sources.

\section{KEYWORDS}

Africans. Social mobility. Savior. XVIII Century.

\section{RESUMEN}

El presente artículo pretende evidenciar cómo el establecimiento de relaciones conyugales informales también representaba posibilidad de mejora de condiciones de vida para la población africana en la Ciudad de Bahía setecentista. Para ello, utilicé la trayectoria de la africana, "mina", Antonia Gomes como ventana privilegiada para comprender esos aspectos y otros relativos al color, género y movilidad social en el contexto de la esclavitud urbana en el siglo XVIII. En efecto, se utilizaron como fuentes inventarios, testamentos, asientos de bautismo y matrimonio.

\section{PALABRAS CLAVE}

Africanos; Movilidad social; Salvador; Siglo XVIII. 
A Cidade da Bahia, como era então chamada a cidade do São Salvador da Bahia de Todos os Santos, foi a capital da América Portuguesa de 1549 até 1763, quando a sede colonial se deslocou para o Rio de Janeiro. Apesar da transferência "persistiram os esforços para tornar Salvador uma das mais estruturadas cidades da colônia, afinal seu papel econômico permanecia significativo no contexto do Império" (SOUZA, 2012, p. 33).

Salvador firmou-se enquanto espaço de concentração de recursos financeiros, econômicos, sociais e políticos propulsores da sua grandeza. Tal cidade, no século XVIII, “há muito ultrapassara a 'Goa dourada' e tornara-se a segunda cidade do Império português, tendo à sua frente, em produção e importância, apenas Lisboa" (BOXER, 2000, p. 148). Uma das maiores cidades exportadoras de açúcar e de fumo da colônia, possuía completa dependência do mercado de mão de obra escrava africana e foi um dos principais portos de desembarque de cativos em todo período colonial.

Eugênio Líbano Soares e Carlos Silva Júnior, utilizando a expressão do viajante francês Freziér, pontuaram que a cidade do Salvador no final do século XVII e início do XVIII parecia uma "nova guiné”, tamanho o contingente de pessoas negras, a maioria de origem africana, por toda parte da cidade, "trabalhando pelas ruas, nos portos, vendendo alimentos, nas casas dos senhores, carregando pessoas e/ou mercadorias" (SOARES; SILVA, 2010, p. 243).

A Cidade do Salvador, em 1757, contava com 6.821 fogos e 37.323 habitantes, segundo Manoel Oliveira Mendes, medidor de obras desta cidade. Thales de Azevedo acrescentou que os dados do medidor baseavam-se nos registros paroquiais, embora esses tenham sido corrigidos. Mendes provavelmente "percorrendo a cidade para fazer a sua descrição, verificou melhor o número de fogos e habitantes, motivo pelo qual devem ser mais exatos os seus números" (AZEVEDO, 2009, p. 157-158). Em 1759, no censo ordenado pelo Conde dos Arcos e pelovice-rei do Brasil, D. Marcos de Noronha, a Cidade da Bahia contava com 6.782 fogos com 40.263 habitantes, excetuando-se os menores de até sete anos, índios e índias de aldeias administradas por ordens religiosas e os religiosos das referidas ordens (AZEVEDO, 2009, p. 157-158).

Em mapa censitário enviado a Lisboa no ano de 1775, pelo Governador Geral Manoel da Cunha Menezes, Salvador apresentava 40.922 almas e 7.080 fogos, ao passo que em seus subúrbios havia 16.093 habitantes e 2.091 domicílios (AZEVEDO, 2009, p. 159). João Reis pontua que de acordo com o censo de 1775, dos 32.253 habitantes de Salvador, $36 \%$ eram brancos; e a população de cor representava nada menos do que $64 \%$ dos moradores da cidade. Destes, 4.207 eram mulatos livres (12\%), 3.630 negros livres $(10,4 \%)$, e 14.696 eram negros e mulatos escraviza$\operatorname{dos}(41 \%)$ (REIS, 2003, p. 22).

\begin{abstract}
A população de cor era notável em todas as partes da cidade. Escravos e forros, africanos e crioulos, além de mestiços de variadas classificações, ocupavam as ruas da cidade. Escravos a serviço de seus amos e/ou de ganho executavam as mais diversas funções: carregadores, domésticos, artesãos, vendedores ambulantes, etc. Numa sociedade onde o trabalho manual era considerado aviltante, uma vez que é o oposto do ideal de nobreza, cabia aos escravos uma infinidade de tarefas braçais. (REGINALDO, 2001, p. 105).
\end{abstract}

Local privilegiado para se encontrar essa população de cor escrava e liberta era a Freguesia de Nossa Senhora da Conceição da Praia, também conhecida como Bairro da Praia no século XVIII. Oliveira Mendes, em 1757, ofereceu cifras relativas à população habitante desta freguesia. Ele contou 868 habitações e 5.464 almas, nas quais entraram as dos marítimos e peregrinos. Cândido Domingues pontua que a multidão de africanos e crioulos que concorriam às bandas da freguesia da Praia para mercadejar toda sorte de produtos e serviços impressionava a quem chegava a Salvador pela primeira vez.

Tal autor acrescenta que ali "milhares de mulheres vendiam diversos alimentos enquanto outros escravos ofereciam serviços que variavam desde 'carregadores' até tarefas de oficiais mecânicos” (SOUZA, 2010, p. 173). Dentre as milhares de trajetórias de vida de africanas que circulavam cotidianamente pela Praia, uma foi possível resgatar no tempo. Vejamos mais de perto. 
Preta mina, liberta, ganhadeira, amásia de um capitão-de-mar-e-guerra português, mãe de dois mulatos legitimados pelo pai, proprietária de escravos. Esses são alguns aspectos da vida de Antonia Gomes na Cidade da Bahia setecentista. Passamos agora a apresentar a trajetória dessa mulher que, apesar de não ter celebrado matrimônio in face Eclésia, viveu maritalmente e desfrutou de certos benefícios da vida de casada.

A análise de tal personagem tem a finalidade de evidenciar a diversidade de modelos de relações conjugais adotados pela população africana na Salvador setecentista, buscando compreender como o estabelecimento de laços possibilitava melhoria das condições de vida para mulheres africanas, no contexto da diáspora. Desse modo, torna-se possível obter uma compreensão abrangente acerca da vida familiar e afetiva dos africanos egressos do cativeiro e assim lançar luz sobre aspectos da história social da escravidão urbana na Cidade da Bahia, na segunda metade do século XVIII.

Antonia Gomes, preta do gentio da Mina, é representante de uma trajetória interessante, merecendo destaque no grupo das mulheres africanas na Cidade da Bahia na segunda metade do século XVIII. É possível imaginar que, nos anos 1730-1740, a preta de nação mina Antonia,circulasse frequentemente pela freguesia da Conceição da Praia e seus arredores a realizar o serviço de ganho, subindo e descendo ladeiras como a da Misericórdia, local onde ela residia com as demais companheiras de cativeiro, escravas ganhadeiras, e o seu senhor, numa casa alugada junto ao padre Francisco Xavier de Pina, pelo valor de 35\$000 (DOMINGUES, 2011, p. 96).

Na freguesia de Nossa Senhora da Conceição da Praia, localizada na chamada Cidade Baixa, existiam muitas lojas de fazendas, miudezas, ferragens, peças para embarcações, drogas, armazéns de molhados, dentre outas. Lá funcionava a Alfândega Geral, o Arsenal, a Ribeira das Naus, a Praça do Comércio, que dava para o mar da Baía de Todos os Santos, uma feira do pescado, na Praça São José, junto à Igreja de Santa Bárbara e o Cais Dourado, onde estavam expostos além de pescados, os frutos da terra, produtos de abastecimento trazidos por meio da Baía (NASClMENTO, 2007, p. 50). Nesses dois últimos locais, muito possivelmente, Antonia Gomes e outras africanas e crioulas ganhadeiras compravam os alimentos que seriam preparados para serem por elas comercializados pelas ruas da cidade.

Acreditamos que, por volta ainda das referidas décadas de 1930 e 1940 dos setecentos, Antonia tenha começado a se relacionar afetivamente com aquele que, além de seu senhor, fora o pai dos seus dois fiIhos: o Capitão de Mar e Guerra Jacinto Gomes ${ }^{1}$, um português natural do Arcebispado de Braga, solteiro, senhor de escravos, residente em Salvador e destacado capitão negreiro da Praça da Bahia². Esse modelo de relação adotado pela africana Antonia e pelo capitão Jacinto Gomes, apesar de peculiar, não passou despercebido aos olhos dos historiadores brasileiros de outras localidades.

Adriana Reis, em sua tese, estudou a família do capitão Manoel de Oliveira Barrozo, proprietário do Engenho Aratu localizado na freguesia de Nossa Senhora de Paripe, no Recônvano da Bahia, pai de seis filhos pardos todos concebidos pela escrava jeje Luzia Gomes de Azevedo e legitimados pelo capitão (REIS ALVES, 2010). Já Júnia Furtado, pesquisou detidamente a afamada trajetória da escrava Chica da Silva e de seu amásio, o Contratador dos diamantes do Arraial do Tejuco, nas Minas Gerais setecentistas (FURTADO, 2003, p. 403).

Antonia, de acordo com Cândido Domingues, desempenhava papel importante na rede social do seu senhor e amásio, na medida em que atuava como madrinha de cativos de outros senhores negreiros conhecidos de Jacinto Gomes, tais como José Francisco da Cruz e Joaquim Inácio da Cruz (SOUZA, 2001, p. 81). Antonia vivia em concubinato com seu senhor e desta relação nasceram dois mulatinhos: Manoel Gomes Bahia e Domingos Gomes Bahia, os quais foram

1. Patente de Capitão de Mar e Guerra Concedida a Jacinto Gomes, Livro de Patentes, Petições e Alvarásn. 357, fL.106 E 107, Seção Colonial, Arquivo Público do Estado da Bahia (APEB).

2. Para mais informações sobre o capitão Jacinto Gomes e capitães negreiros na Bahia ver a dissertação de Cândido Domingues de Souza. 
reconhecidos em testamento como filhos naturais e herdeiros de Jacinto Gomes, em 1752, ano de falecimento do capitão ocasião na qual ele explicitou,

\begin{abstract}
Declaro que sou solteiro e nunca fui casado sem encargo de que tenho dois filhos naturais havidos em uma escrava minha Antonia, um por nome Domingos e outro Manoel ambos mulatos, os quais são meus herdeiros forrados [...] e os declaro para haverem de [...]dade meus bens o que diretamente the tocar por folha de partilhas [...]" [...] Declaro que a preta Antonia e mais dois mulatinhos é forra por carta de liberdade que the dei a quem também dei uma escrava por nome Joanna que a de constar escrito [...] que the passei, a qual também possui uma moleca por nome Narciza que também é sua ${ }^{3}$.
\end{abstract}

Quando da morte de Antonia Gomes, em 1758, ambos os filhos foram descritos em seu inventário como maiores e participaram do inventário assinando, inclusive, o que nos leva a crer que eles nasceram no mínimo no ano de $1740^{4}$ e que não tiveram o destino cativo da sua mãe, já que tiveram acesso à alfabetização.

Antonia Gomes não aparenta ter sido apenas uma escrava que teve filhos com o seu senhor, prova disso é a concessão de alforria realizada e ratificada por Gomes quando da escrita do seu testamento, além do reconhecimento da paternidade dos filhos. Soma-se a isso o presente dado por Jacinto a Antonia: duas escravas uma chamada Joanna e outra nomeada como Narcisa, ainda moleca. É possível que tais escravas tivessem a função de auxiliar Antonia Gomes nos serviços domésticos e também realizassem o ganho para auferir renda com objetivo de contribuir com a manutenção da casa, já que a senhora necessitava de tempo para cuidar dos herdeiros do capitão.

Mas não consideramos lícito pensar que Antonia Gomes tenha simplesmente se tornado uma dona de casa e tivesse deixado definitivamente o trabalho ao ganho, que the conferia sua independência financeira. Como afirmou Sheila Faria, os libertos que possuíam escravos visavam acumular pecúlio com o traba-

3. Testamento e Inventário de Jacinto Gomes, fl. 3v, n. de Classificação 1752 03/1147/1616/02. (APEB).

4. Inventário de Antonia Gomes, fl. 16, n. de Classificação 05/2048/2519/17. (APEB).
Iho conjugado. "Ao que tudo indica, mesmo quando alforriados e enriquecidos, continuavam a exercer as atividades que executavam enquanto escravos" (FARIA, 2014, p. 162-163).

Antonia teve seu testamento datado a 14 de novembro de 1758, mas afirmou que o tinha há tempos feito e que "por me ser preciso declarar neste codicilo alguma circunstância faço este dito codicilo para efeito de declarar [...]" quando se encontrava doente ${ }^{5}$. Declarou a africana, que deve "a Antonio Gomes do Rozario de dinheiro que me tem suprido, para meus gastos, e juizado a quarenta e quatro mil e quatrocentos reis, que ordeno se lhe satisfaça prontamente sem contenda de justificação".

Tudo leva a crer que tal credor de Antonia seja o ex-escravo marinheiro do capitão Jacinto Gomes, que comprou a própria alforria reconhecida pelo testamenteiro Domingos Pereira Bastos e pelos dois herdeiros de Jacinto, em nove de novembro de 1753, por $130 \$ 000$ réis (SOUZA, 2011, p. 115). Desse modo, a amizade entre Antonia e Antonio existia desde os tempos do cativeiro e o liberto lograra alguma renda que lhe permitiu até conceder empréstimos de quantias não desprezíveis.

Localizei mais indícios sobre Antonio Gomes do Rozario. Doze anos após conquistar a sua alforria, em 14 de novembro de 1765, o preto aparece nos termos de batismo da freguesia de N. S. da Penha como senhor de uma escrava chamada Benedita, que na ocasião batizava a sua primeira filha, a crioula Maria. 0 padrinho da criança foi Francisco de Moura, preto, forro e morador da freguesia da Praia 7 . Em 29 de março de 1767 Benedita batizava mais uma criança, Leandro, crioulo. Foram padrinhos da criança Amado Mendes Teixeira, pardo, forro e Brízida de Assunção, preta, forra, viúva, todos moradores na Penha ${ }^{8}$.

5. Testamento de Antonia Gomes, fl. 9, n. de Classificação 05/2048/2519/17. (APEB).

6. Testamento de AntoniaGomes, fl. 9 n. de Classificação 05/2048/2519/17. (APEB).

7. Livro de termos de batismos da freguesia da Penha - 1762-1799. (ACMS), $14 / 11 / 1765$.

8. Livro de termos de batismos da freguesia da Penha - 1762-1799. (ACMS), 29/03/1767. 
Em 26 de novembro de 1769, Gonçalo, solteiro e morador da freguesia da Praia batizou o terceiro filho de Benedita, Victorino, crioulo9 ${ }^{9}$. No décimo dia do mês de janeiro de 1773 foi batizada Ritta, crioula, a quarta filha da crioula escrava de Antonio Gomes ${ }^{10}$ e em 15 de março de 1775 foi a vez de Antonio, crioulo, quinto filho de Benedita, receber os santos óleos. Seu padrinho foi Braz Antonio Coimbra, na época solteiro e morador da freguesia da Penha ${ }^{11}$. Percebe-se, assim, que Antonio Gomes possuía no mínimo 6 escravos: Benedita e seus 5 filhos, o que era bastante significativo para um egresso do cativeiro.

Declarou José da Silva Barros, voltando a Antonia Gomes, inventariante da defunta, que "ficarão [...] de abstenção da herança seus filhos, por causa das muitas dívidas [...]" de modo que se fez arrematar na praça, os bens e os escravos em perigo de morte para saldá-las ${ }^{12}$.

0 inventariante conseguiu vender alguns bens da falecida, "porém uma preta doente por nome Rita, com sua cria, e uma crioulinha de quatro anos por nome Anna se não arremataram no dia doze. [...] A dita preta Rita é doente [...]". O inventariante encontrou dificuldades na arrematação das ditas escravas e recomendava toda brevidade na resolução desta causa já que alguma das ditas pretas poderia morrer ${ }^{13}$.

Diante da análise desses aspectos da trajetória de Antônia Gomes surge a questão: porque ela e Jacinto Gomes não celebraram união católica? Em estudo sobre a relação consensual de um destacado senhor de engenho do Recôncavo baiano com sua escrava, Adriana Dantas Reis, levantando hipóteses tendo em vista responder à pergunta sobre o porquê do Capitão Barrozo não ter se casado com Luzia jeje, afirma, inicialmente, que tal sujeito pode não ter encontrado

\footnotetext{
9. Livro de termos de batismos da freguesia da Penha - 1762-1799. (ACMS), 26/11/1769.

10. Livro de termos de batismos da freguesia da Penha - 1762-1799. (ACMS), 10/01/1773.

11. Livro de termos de batismos da freguesia da Penha - 1762-1799. (ACMS), 15/03/1775.

12. Inventário de Antonia Gomes, fl. 20, n. de Classificação 05/2048/2519/17. (APEB).

13. Inventário de Antonia Gomes, fl. 30, n. de Classificação 05/2048/2519/17. (APEB).
}

uma mulher do seu mesmo nível social, apta a se casar (que deveria ser, de preferência, branca e, fundamentalmente, de uma família que pudesse pagar um considerável dote).

Posteriormente, a autora acrescenta que prefere acreditar que o senhor cultivava sentimentos de afeto e de família por sua escrava e seus filhos, porém afirma não querer dizer com isso que "não houve preconceito nem violências sexuais contras as mulheres negras, consideradas como mais vulneráveis, mas tê- las como potencialmente sensuais também abriria brechas e possibilidades" (REIS, 2010, p. 149-150). Segundo Reis, as mulheres de cor, pretas, crioulas e pardas, historicamente interpretadas como afastadas dos espaços de poder, ao serem encaradas como sinônimo de beleza, desejo e prazer, apresentavam reais possibilidades de mobilidade social para si e para sua prole.

Tais interpretações podem ser estendidas à situação de Antonia e Jacinto Gomes. Júnia Furtado sinaliza que, na sociedade colonial, o casamento estava encerrado em regras e condições e que a desigualdade social, racial e de origem entre os cônjuges era motivo forte para dificultar e mesmo impedir os matrimônios legais. 0 Estado português, por processos em que eram averiguadas as origens dos nubentes, normalmente não permitia o casamento entre indivíduos de condições desiguais. Mulheres negras ou mulatas casavam-se apenas com homens de igual condição. Para a autora, "a falta de consortes aptas, principalmente mulheres brancas, fez com que as uniões consensuais entre indivíduos de condições desiguais se tornassem comuns" (FURTADO, 2003, p. 85).

Adriana Reis constatou que para o Recôncavo baiano setecentista tal tese relativa à carência de mulheres brancas aptas a casar não tem validade, pois o Capitão Barroso, amásio de Luzia jeje, também teve uma filha com uma mulher branca, por exemplo. Para Reis, relacionar-se com mulheres negras não representava uma falta de opção desses senhores, mas sim opção e decisão, tese à qual somos simpáticos para interpretação da trajetória de Antonia Gomes (REIS, 2010, p. 148-149). 
Segundo Katia Mattoso, o concubinato estava tão enraizado na sociedade soteropolitana, no século XIX, que ninguém se preocupava em escondê-lo, mesmo nas camadas mais abastadas (MATTOSO, 1992, p. 135). Isso porque

\section{[...] uma tradição de celibatos e de famílias consen- suais nasceu e criou profundas raízes na sociedade baiana. Tanto os humildes, às vezes pobres demais para assumir as despesas de uma cerimônia religiosa, quanto os abastados recuavam diante das imposições do casamento legal, como, por exemplo, a educação dos filhos e a obrigação de sustenta-los. (MATTOSO, 1992, p. 135).}

É inegável o fato de que muitos homens abastados tenham recusado assumir seus filhos, educá-los e sustentá-los, como afirma Mattoso, mas esse não foi o caso da personagem aqui analisada, como apresentarei nas linhas que se seguem. Também não foi o caso do Capitão Manoel de Oliveira Barrozo, estudado por Adriana Reis, o qual legitimou os seis filhos que teve com a sua escrava Luzia jeje, os quais moravam com o pai, foram educados por ele e até auxiliavam (o primogênito especialmente) na administração e multiplicação dos bens da família, tornando-se legítimos herdeiros dos bens do capitão, quando da sua morte (REIS 2010).

Apesar do "impedimento" ao casamento entre desiguais, por assim dizer, localizamos uma união entre cônjuges de cor, condição jurídica e origens diversas, assim como Antonia e Jacinto, celebrando o matrimônio católico no mesmo período e cidade, na freguesia de Nossa Senhora da Sé. Trata-se de um caso pouco comum na historiografia brasileira sobre a família. Celebraram o sagrado matrimônio, em 25 de maio de 1771,

De tarde em casa da contraente por se achar em artigo de morte, sendo dispensados dos contraentes nos banhos e jurando não ter impedimento algum [...]Luiz de Souza [...], homem branco natural da freguesia de Santo Antonio Além do Carmo e morador nesta Sé, exposto em casa do Alferes José de Souza Brito, já defunto [...] [se uniu a] Rosa Soares Pinheiro, preta forra, natural da Costa da Mina e moradora também nesta Sé. Testemunhas: Padre Pedro Ferreira dos Santos
Coadjutor da freguesia de Nossa Senhora da Penha, o Padre Claudio Martins do Rio da freguesia do Pilar, João Batista de Lima, Pedro Gomes Ribeiro, Carlos da Paz, casados, desta freguesia, José Caetano da Trindade da freguesia do Santíssimo Sacramento da Rua do Paço, Antonio de Souza, pardo solteiro, da freguesia da Conceição da Praia, Veríssimo Pedro de Alcantara, casado da freguesia de Sam Pedro, José Thimoteo de Souza, casado, da freguesia de Santa Anna e Joaquim Pereira, solteiro da freguesia de Santo Antonio e outras pessoas mais que presentes se acharão. 0 Vigário foi o Coadjutor Antonio Teixeira dos Santos ${ }^{14}$.

Essa cerimônia demonstra que, apesar das barreiras para o casamento entre "desiguais", alguns casais conseguiram furar o bloqueio ${ }^{15}$. Muito provavelmente, o fato de a cônjuge estar em risco de morte pesou na decisão dos religiosos de autorizar a união. E uma das motivações do casal para a oficialização da união, nesse caso, pode ter sido a proteção dos bens da africana. Sendo Rosa Soares uma preta, forra, solteira aos olhos das autoridades, seus bens ficariam para 0 Estado, no caso da ausência de filhos. Daí a premência na realização do matrimônio.

Não obstante as dificuldades financeiras enfrentadas por Antonia Gomes no fim da sua vida, acredito que se pode afirmar que a trajetória desta africana diferencia-se bastante das trajetórias da maioria das mulheres egressas do cativeiro em Salvador, na segunda metade do século XVIII. Isto por muitos motivos, dentre eles porque um número significativo de pessoas vítimas do cativeiro morreram sem jamais sentir o sabor da liberdade e outra infinidade se conseguia a alforria, sobrevivia em condições precárias de saúde, habitação e alimentação (KARASH, 2000).

Antonia se relacionou com seu senhor, teve dois filhos com ele, os quais foram reconhecidos como herdeiros, obteve alforria gratuita, se tornou companheira do seu ex-senhor, ganhou duas escravas, mo-

14. Livro de termos de casamento da freguesia da Sé, 1752-1777, 25/05/1771.

15. Adriana Reis também localizou um casamento entre cônjuges de cor, condição e origem diferentes. "0 casamento, em 1804, de Manoel Joaquim de Moura Pacheco, homem branco, que vive de roça, com 30 anos, filho legítimo e nascido em Braga, Portugal, que se casou com AntoniaSilvéria do Amor Divino, parda, forra, com 20 anos, filha legítima de Gonçalo [Correia] e Roza Maria de Santo Amaro" (REIS, 2010, p. 119). 
rava na casa com ele e gozava, por vezes, do status de senhora, uma vez que o senhor era capitão negreiro e vivia a viajar pelas rotas do tráfico deixando-a com os filhos, com as suas cativas e com as escravas de ganho em casa. Tais elementos permitem afirmar que podemos considerar a trajetória de Antonia Gomes uma trajetória de razoável mobilidade social.

Adriana Reis, inspirando-se em Hebe Mattos, pontuou que a mulher cativa, para os escravos, era como uma "ponte" rumo a experiências familiares e de autonomia; e para os senhores, elas poderiam ser uma "fonte" de prazer sexual, e, assim, eram esses que se tornavam 'pontes' de acesso a vantagens (REIS, 2010, 132-133). Rangel Cerceau, discutindo as uniões consensuais em Minas Gerais, também destacou a importância delas para a mobilidade social dos sujeitos envolvidos. Segundo ele foi “[...] entre o público feminino que a mobilidade social aconteceu com grande pujança, refletindo um elevado contingente de mutheres e filhos que, inclusive por meio do concubinato, conseguiram mudar a condição sócio jurídica de escrava para forra”. (CERCEAU, 2008, p. 79).

Na mesma linha de raciocínio Júnia Ferreira Furtado destacou que

As mulheres escravas e forras, uma vez alçadas à condição de concubinas de homens livres, tiveram grande possibilidade de ascensão na sociedade colonial, usufruindo, muitas vezes, das vantagens que a concubinagem podia oferecer-lhes, como alforrias e melhores condições de trabalho, a fim, é claro, de minimizar os estigmas da escravidão. (FURTADO, 2003, p. 22).

Tais vantagens da relação consensual foram percebidas na trajetória de Antonia Gomes. É possível afirmar que ao estabelecer laços afetivos com seu senhor, Antonia garantiu certos recursos materiais para seu futuro, ao gerar filhos de Jacinto (que foram legitimados) e adquiriu melhores condições de vida, na medida em que conquistou alforria e se tornou senhora de escravos, ao ter sido presenteada com duas cativas pelo amásio. Percebe-se, então, que apesar de Antonia não ter celebrado um casamento nos moldes tridentinos, ela pode gozar de certos benefícios presentes, principalmente, numa relação conjugal formal.

Visto isso, é possível levantar alguns possíveis significados para a união consensual entre Antonia e Jacinto. Primeiramente, tal união aparenta ter sido vantajosa para ambas as partes: para Antonia que deixou sua vida de cativa para tornar-se mãe dos filhos do capitão e para Jacinto, homem do mar, estrangeiro numa terra desconhecida, que precisava de um lar e cuidados quando das suas voltas ao solo soteropolitano. Desse modo, é plausível afirmar que um dos significados dessa união tenha sido o auxílio mútuo, o companheirismo presente não apenas nas uniões sacralizadas pela Igreja. Nesse sentido, tal formato de união atendia a muitas necessidades do casal.

A importância dessa união, ainda que informal, para Antonia parece tamanha que após a morte de Jacinto ela contraiu consideráveis dívidas. É imaginável que tenha sido difícil para Antonia, mãe de dois filhos ainda menores quando da morte do pai (ainda que herdeiros), custear sozinha o aluguel e a manutenção da alimentação da família e das escravas.

A união consensual de Jacinto e Antonia apresenta ainda mais importância para trajetória de tal africana, na medida em que legou a ela uma prole livre dos grilhões do cativeiro e dos estigmas conferidos aos homens e mulheres pretos na América Portuguesa. Referimo-nos aqui a Manoel e Domingos Gomes Bahia, mulatos, ambos reconhecidos e legitimados pelo pai em testamento, tornando-se seus herdeiros. Os dois mulatos tiveram acesso a educação, o que pode ser observado no inventário da sua mãe, quando ambos, já maiores de idade, assinaram o documento. Percebem-se, desse modo, traços da mobilidade, no sentido ascendente, proporcionada aos filhos ilegítimos de Antonia Gomes, por meio da sua relação de concubinato com o capitão negreiro português. 
Figura 1 - Assinatura de Manoel Gomes Bahia e Domingos Gomes Bahia.

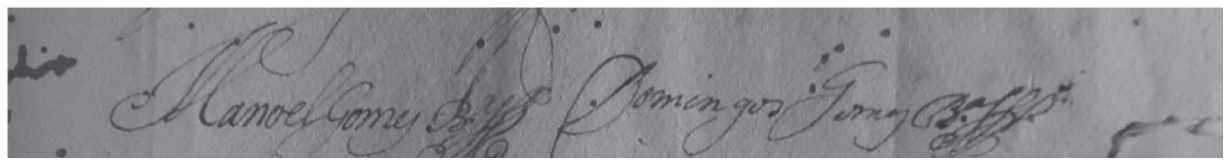

Fonte: Inventário de Antônia Gomes. N.05/2200/2669/04, Fl. 18f. Seção Judiciário, APEB.

Outros indícios de mobilidade na trajetória desses mulatos puderam ainda ser constatados. Se Jacinto Gomes e Antonia Gomes não sacralizaram suas uniões, seus filhos e neta o fizeram. Tal fato é demonstrativo da valorização do sétimo sacramento católico por parte desses sujeitos, que possivelmente sabiam o valor social desta formalização da união e utilizaram-no objetivando adquirir os benefícios que o status de casado e que a constituição de uma família estável proporcionava àqueles que 0 acessavam.

No dia 24 de outubro de 1753, o mulato Manoel Gomes Bahia, filho natural de Jacinto Gomes e Antonia Gomes, se casou na igreja Matriz de Nossa Senhora da Conceição da Praia com Romana Lourença de Souza, filha legitima de Antonio Meirelles e de Paula Correa, ambos falecidos (SOUZA, 2011, p. 82). Manoel Gomes Bahia teve uma filha, a qual nomeou Marcelina Gomes do Rozário, parda. No dia 19 de abril de 1773 , vinte anos após o casamento dos seus pais e do falecimento do seu avô, Marcelina, à época órfã de pai, casou-se com Antonio Moreira, pardo, filho legitimo de Antonio Moreira e de sua mulher Caetana Maria da Conceição. Dentre as testemunhas desta união estavam Francisco José da Fran[ca] e Santos Antonio Paes, solteiros, ambos moradores na freguesia da Penha ${ }^{16}$.

Já Domingos Gomes Bahia se casou com Joana Gomes do Rozário, em 18 de abril de $1776^{17}$. Pouco mais de um ano após a celebração do matrimônio Domingos e Joana batizaram a pequena Ana, cabra, no dia 20 de julho de 1777. Foi padrinho da criança José Ricardo, casado e morador da freguesia da Conceição da Praia ${ }^{18}$.

16. Livro de termos de casamento da freguesia da Penha - 1762-1831. (ACMS), 19/04/1773.

17. Livro de termos de casamento da freguesia de Nossa Senhora da Penha - 1762-1831. (ACMS), 18/04/1776. 0 documento está parcialmente ilegível impossibilitando a leitura do nome dos pais da noiva e demais informações. 18. Livro de termos de batismo da freguesia da Penha - 1762-1799. (ACMS), 20/07/1777.
Manoel Gomes Bahia, apesar de mulato e filho de uma ex- escrava casou-se com uma filha legítima, órfã de pai e mãe, com a qual teve uma filha de nome Marcelina, classificada com parda. Tal categoria pode indicar que esta última galgou um lugar social diferente daquele ocupado por seu pai, tendo em vista que o termo pardo, quando aplicado a livres, pode ser representativo não apenas do distanciamento geracional em relação ao cativeiro, mas também de 'uma posição distinta, em relação a outros descendentes de escravos ou forros (pretos e negros) e a (brancos)' (GUEDES, 2008, 98).

Adriana Reis acrescenta que a depender dos mecanismos de ascensão de indivíduos de cor, esta poderia inclusive, desaparecer dos registros. Segundo a autora, "nos assentos de batismo e casamento, as ausências de cor possuem determinantes variados e dependem do olhar de quem os registra, e esse olhar pode ser influenciado pela posição social", como foi constatado nos casos dos filhos pardos do capitão Barrozo (REIS, 2013, p. 57-58)

Marcelina, por sua vez, também se uniu a um filho legítimo classificado como pardo. A descendência da africana Antonia Gomes afastava-se assim, cada vez mais do passado escravo da matriarca. Tal trajetória permite interpretar que não apenas a vida de casado oficialmente conferia significativos benefícios sociais que representavam motivações para o acesso ao mesmo e constituíam um fator importante na vida dos africanos libertos na cidade da Bahia setecentista. O concubinato plurirracial, a união consensual duradoura, poderia proporcionar significativa mobilidade social no sentido ascendente, especialmente para as mulheres, não apenas na região das Minas Gerais e no Recôncavo Baiano, como também na Salvador setecentistas, como pôde ser visto na trajetória da africana Antonia Gomes. 
Porém inegável é o fato de que se Antonia e Jacinto Gomes houvessem celebrado sua união nos moldes tridentinos as condições materiais de vida da africana após a morte do capitão possivelmente seriam melhores, visto que ela, assim como os filhos legitimados, se tornariam herdeiros, já que na época do Brasil colonial e imperial os casamentos celebrados sem acordo pré-nupcial eram todos de "carta de a metade", o que chamamos hoje de comunhão de bens.

Tudo isso evidencia como os enlaces, sancionados pela igreja ou não, podiam propiciar melhores condições de vida para os sujeitos envolvidos, especialmente para as mulheres de cor, cujas representações como sinônimo de beleza, desejo e prazer povoavam o imaginário dos homens do período colonial. Assim, evidencia-se como mulheres pretas como Chica da Silva, Luzia Gomes e Antonia Gomes, dentre tantas outras cujas pesquisas revelaram, são exemplos de "Mulheres negras por cima".

\section{REFERÊNCIAS}

ANTONIL, André João, Cultura e opulência no Brasil por suas drogas e minas. Belo Horizonte: Itatiaia; São Paulo: USP, 1982 [1711].

\section{AZEVEDO, Thales de. Povoamento da cidade do}

Salvador. Edição Fac-similar. Salvador: Fundação Pedro Calmon, 2009.

BOXER, Charles. A idade de ouro no Brasil: dores de crescimento de uma sociedade colonial. 3.ed. Rio de Janeiro: Nova Fronteira, 2000.

\section{CERCEAU NETTO, Rangel. Um em casa de outro:} concubinato, família e mestiçagem na comarca do Rio das Velhas (1720-1780). São Paulo: Annablume; Belo Horizonte: UFMG, 2008.

FARIA, Sheila Siqueira de Castro. Sinhás pretas, damas mercadoras: As pretas minas nas cidades do
Rio de Janeiro e de São João Del Rey (1700-1850). 2004. 278f. Tese (Doutorado) - Departamento de História da UFF - Concurso para titular em História do Brasil. Niterói, 2004.

\section{FURTADO, Júnia Ferreira. Chica da Silva e o}

contratador de diamantes: o outro lado do mito. São

Paulo: Companhia das Letras, 2003.

\section{HORA, Raiza Cristina Canuta da. Sob os olhos do}

Bonfim: Africanos em suas vivências matrimoniais, familiares e sociabilidades na Cidade da Bahia no século XVIII: A freguesia de N. S. da Penha de Itapagipe: (1760-1808). Dissertação (Mestrado em História) - PPGH/UFBA, Salvador, 2015.

GUEDES, Roberto. Egressos do cativeiro: trabalho, família, aliança e mobilidade social. Porto Feliz São Paulo, c. 1798- c.1850. Rio de Janeiro: Mauad X: FAPERJ, 2008.

JANCSÓ, Istvan. Na Bahia, contra o Império: história do ensaio de sedição de 1798, São Paulo/Salvador: Hucitec/Edufba, 1996.

\section{KARASH, Mary C. A vida dos escravos no Rio de} Janeiro: 1808-1850. São Paulo: Companhia das Letras, 2000.

MATTOSO, Kátia M. de Queirós. Bahia, século XIX: uma província do Império. Rio de Janeiro: Nova Fronteira, 1992.

MATTOSO, Kátia M. Bahia opulenta: uma capital portuguesa no Novo Mundo (1549-1763), In: Da revolução dos alfaiates à riqueza dos baianos no século XIX: itinerário de uma historiadora, Salvador: Corrupio, 2004.

NASCIMENTO, Anna Amélia Vieira. Dez freguesias da cidade do Salvador: Aspectos sociais e urbanos do século XIX. Salvador: EDUFBA, 2007. 
OLIVEIRA, Maria Inês Côrtes de. 0 liberto, seu mundo e os outros: Salvador, 1790/1890. Salvador: Corrupio, 1988.

REIS ALVES, Adriana Dantas. As mulheres negras por cima: 0 caso de Luzia jeje: Escravidão, família e mobilidade social - Bahia, c. 1780- c. 1830. Tese de doutorado. Niterói: UFF, 2010.

REIS ALVES, Adriana Dantas. Pardos na Bahia: casamento, cor e mobilidade social, 1760-1830.

Perspectivas, Poutuguese Journal of Political Science and Intenational Relations. N.10, Jun. 2013.

REIS, João José. Rebelião escrava no Brasil: a história do levante dos Malês em 1835. São Paulo: Companhia das Letras, 2003.

REGINALDO, Lucilene. Os rosários dos angolas: Irmandades de africanos e de crioulos na Bahia setecentista. São Paulo: Alameda, 2011.

RIBEIRO, Alexandre Vieira. 0 tráfico Atlântico entre a Bahia e a Costa da Mina: flutuações e conjunturas (1683-1815). Estudos de História, Franca-SP, v.9, n.2, 2002.

RIBEIRO, Alexandre Vieira. 0 tráfico atlântico de escravos e a praça mercantil de Salvador, c. 1830. Dissertação (Mestrado) - UFRJ, Rio de Janeiro, 2005.

RIBEIRO, Alexandre Vieira. A cidade de Salvador: estrutura econômica, comércio de escravos, grupo mercantil (c. 1750-c.1800). 2009. Tese (Doutorado) UFRJ, Rio de Janeiro, 2009.
SCHWARTZ, Stuart B. Segredos internos: engenhos e escravos na sociedade colonial: 1500-1835, São Paulo, Cia das Letras, 1999.

SILVA JÚNIOR, Carlos Francisco da. Identidades afro-atlânticas: Salvador, século XVIII (17001750). 2011. 251f. Dissertação (Mestrado) - UFBA, Salvador, 2011.

SOARES, Carlos Eugênio Líbano; SILVA JÚNIOR, Carlos Francisco da. Uma nova Guiné: Africanos em inventários e registros de batismo na Cidade da Bahia da primeira metade do século XVIII. História UNISINOS, v.14, n.3, setembro/dezembro, 2010.

SOUZA, Cândido Eugênio Domingues de. Perseguidores da espécie humana: capitães negreiros da Cidade da Bahia na primeira metade do século XVIII. 2011. 217f. Dissertação (Mestrado) UFBA, Salvador, 2011.

SOUZA, Avanete Pereira. A Bahia no século XVIII: poder político local e atividades econômicas. São Paulo: Alameda, 2012.

SOUZA, Avanete Pereira. Na Praya de Nossa Senhora e dos Traficantes: Comércio e Sociabilidades na Cidade da Bahia Setecentista. Plurais: revista multidisciplinar da UNEB, v.1. n.1. (jan.abr.2010) Salvador: EDUNEB, 2014.

SOUZA, Daniele Santos de. Entre o "serviço da casa e o ganho": escravidão em Salvador na primeira metade do século XVIII. 2010. 159f. Dissertação (Mestrado) - UFBA, Salvador, 2010. 
